\title{
Sport, Public Relations and Social Media
}

\section{Raymond Boyle and Richard Haynes}

Sport is simultaneously a global phenomenon and a local and personal one. It is simultaneously a gigantic commercial business and a gigantic voluntary enterprise [] Sport fulfils all of these conflicting roles in global society through a multi-layered and mutually dependent relationship with the media and other commercial interests. There is no simple definition of what modern sport stands for and therefore no simple solutions to its many problems.

Mihir Bose, (2012) The Spirit of the Game: How sport made the modern world, page 570 .

\section{Introduction: Asking the right questions of networked media sport}

Sport has long been a medium through which marketing communications have sought to capture an audience for commercial services and goods, and for participation in a sport itself. Nineteenth century sports newspapers and pamphlets carried advertising for the latest tonic for a healthy body, or the latest innovation in lawnmower technology to enable the suburban upper middle classes to have pristine lawns for tennis and croquet. Victorian and Edwardian sports administrators took to using pseudonyms as they engaged in early forms of sports journalism, in an effort to both inform and persuade their public about the wonders of their sport or to lobby for changes in the organisation or rules of the game (Vamplew, 2004). Media relations have therefore always formed an aspect of sport, and the historical connection between sport, communications and what we now understand as the promotional industries of advertising, marketing and public relations is both long and strongly interlocked with the operational activities of most sports administrators, teams, leagues', governing bodies, athletes and associated agencies. 
Unpicking the complexity of these interrelationships is no easy matter. The nexus around which sport engages with media and communications has gained even more complexity since the development of the Internet and what Brett Hutchins and David Rowe have labelled 'networked media sport' - 'the movement away from broadcast and print media towards digitized content distributed via networked communications technologies' (Hutchins and Rowe, 2012: 5). More recently, the evolution of mobile social networked media has given a more direct public voice to athletes who are cosseted from mainstream media outlets by agents and communications managers, but at the same stroke, are given a new freedom of expression through sites and applications such as Facebook and Twitter to engage with their fans. The variegated nature of the relations between athletes, sponsors, the media, and fans means that communications strategies of sports organisations are more differentiated than ever before, and understanding the flows of communication between the different stakeholders is a challenge. The plenitude of content created by networked media sport is so expansive that it is increasingly difficult to fully comprehend the multitude of ways in which sport relates to new communications technologies. This is not only an issue for academic researchers of the sport-media nexus, but also for the sports industries, the media industries and consumers of sport alike.

Historically, and for nearly half a century, television has dominated the sports media landscape, maturing to a state where the political economy of elite professional sport ticked over to its every whim. But with networked media sport, the screens on which sport is produced, distributed and consumed are 
multiple, delivered in an array of formats and consumed in differential and mobile spaces. This is not to argue that television has become less important. It remains one of the key platforms that supporters and fans engage with sport through, and crucially, remains a key platform in allowing key sports events to resonate with an audience beyond the dedicated sports fan. The television audiences for the London 2012 Olympics and Paralympics in the UK on free-toair television were impressive and indicative of the enduring appeal of watching sport on this particular screen. However, networked media sport will arguably change the nature of the TV-sport relationship, and the demands of television executives and advertisers are inflected with quite different business models and economic imperatives, which are no longer directly in their control. One obvious example here is the rise of television piracy (so called), which in terms of sports content is a virulent global phenomenon, that potentially undermines the media rights models of exclusive contracts, national markets, pay-walls and a rights regime that has given some sports untold riches. While other online companies such a Dailymotion and YouTube spent much of 2012 acquiring the online streaming rights to various forms of sports content from the Wimbledon tennis championship (Dailymotion) to French Ligue 1 football (Dailymotion, YouTube).

In such a volatile and evolving media environment there is a need to know how sport has responded to such challenges. To what extent is sport a key driver of new media technologies and their uptake, and alternatively, in what ways is its symbiotic relationship with television a conservative force blocking new modes of communication. Do the various actors and agencies in media sport use social networked media in the same way, and if not, how are they differentiated. 
Finally, what strategies, guidelines and regulations have been introduced to manage networked media sport and its stakeholders, and how do they impact on the media relations of athletes, teams and governing bodies of sport. In what follows, we first outline the approach of corporate sponsors of sport to public relations and networked media sport. We then map out the ways in which sports organisations and athletes have responded to networked media, and then invert the question to ask what media organisations, particularly the press and television, have done to adapt their practices to the demands of networked media.

\section{Sport Sponsorship, Public Relations and Social Media}

In the context of sports public relations and communications management, network media sport has also introduced new opportunities and challenges for both sports industries and the media. As Lewis and Kitchin (2011: 208) have noted, the 'social web' has enabled corporate sport to break down barriers between the organisation and its consumers by creating 'more tangible and vibrant relationships'. Sport has always helped drive the uptake of new communications technologies, and the practices of journalists, broadcasters and public relations professionals has often had to fit with the culture of sport in quite distinct and unique ways. With the rise of social networked media we might want to ask if this remains the case. Has the evolution of the Internet and the digital cultures that have been inspired and created from it, transformed the ways in which sport now engages with the media. Or, are their continuities in what sport delivers to networked media sport, in terms of its cultural and economic value. 
One way in which it is possible to approach such questions is to explore the market-driven discourse of elite professional sport, and look at some of the recent market research and intelligence available and circulated among those who work in the sports industries and the associated cultural industries that gravitate around it. Again, as Hutchins and Rowe (2012) have argued, much of the rhetoric that surrounds the discourse of sports and media industries is mere boosterism, an attempt to inflate 'the new' in new media, and promote a sense of radical change when incremental developments occur. The language of sport in this context is one of branding, sponsorship, event management, public relations, and television rights and, most crucially in the context of digital communications, social media activity.

It is useful to draw on the data produced by this industry when examining the impact of socially networked media on sport because it tells us something about the strategic goals of both major sports organisations and the commercial partners they connect with. Both have turned to social media as a public relations and marketing tool. Both have arguably a long way to go before their analysis of what is happening in this domain of communications provides any tangible understanding for the social and cultural engagement with sport via the Internet. Advertisers demand consistency in appraising the economic value of investment in sport. The greatest risk for advertising in sport is the uncertainty of return from expenditure, and there is a need to know how effective a campaign has been (Gratton et al, 2012). Sponsorship, which is a function of both the advertising and wider public relations activity of a company, presents further 
risks, not least because of the multiplicity of objectives any one sponsors might have for their investment in sport (for, example, building brand image and visibility, corporate hospitality, launching new products, and so on). When combined to the complex social relations of networked media sport, how the sports industries and their sponsors evaluate social media activity remains a murky science. One thing we might want to investigate, therefore, is how global sports organisations and their sponsors approach media research in this context, and what kinds of questions are being asked.

For example, early market data from the London 2012 Olympic Games, heralded in some quarters as the 'Social Olympics', revealed that a number of the International Olympic Committee's blue-chip Olympic Partner (TOP) sponsors gained what they perceived to be huge traction from viral social marketing campaigns via sites such as Twitter, Facebook and YouTube. In the lead up to London 2012, between 18 April and 29 June, the global consumer product corporation Proctor and Gamble created what was termed a 'social media buzz' with more than 17,000 posts mentioning their brands in connection to the Games. This far outstripped the 'buzz' generated by other TOP sponsors such as Samsung, Visa, Coca-Cola, Acer, Dow Chemical, General Electric, Omega, McDonald's and Atos by some considerable margin (Sport Business International, August 2012, No.181, p.4). While the need for major sports sponsors to measure the effectiveness of social media campaigns is merely an extension of a longestablished model of market research around sport, the reporting of Proctor and Gamble's 'success' in this field, suggests a shift in priorities in the commercial strategies of global corporations and sport. The scale of the 'buzz' was equated 
with an improved 'sentiment' by consumers towards their leading brands, which is arguably highly subjective, but nevertheless taken as a serious indicator to justify the $£ 1.4$ billion invested by the company in London 2012 (The Independent, 16 July 2012).

Critical approaches to social networked media (Boyd and Ellison, 2007) have noted that the 'bean counting' approach to Twitter 'followers' or YouTube 'likes' only tells a partial story of engagement with such media texts, and indeed, tells us absolutely nothing about the qualitative experience of clicking through and reading or watching such material online, which is further complicated by the technologies being used to access social media which ranges from mobile phones, personal computers and tablet devices. Social media have moved to accommodate such criticism, for instance in October 2011 Facebook introduced a new metrics system called 'Talking about this' which measures unique users who make a story, on top of which another metric measures the 'engagement ratio' to account for the depth of any encounter with stories and threads.

Although marketing companies may have introduced more subtle and nuanced metrics to interpret what is going on in the world of social media, there is a sense to which the presence of corporate logos and official social media sites of global corporations is both unwelcome and indeed, largely ignored by the majority of users of such technologies. Take for example, this reaction in a reader comment to The Independent newspaper in July 2012, by no means isolated, to the news that sponsors were clamping down on ambush marketing around London 2012: 
How is it possible that the words 'gold, silver and bronze' can be appropriated by corporate sponsors, let alone 'summer'? Will the London Metal Exchange be shut down for the duration? And the Met Office?

At least the article obligingly provides me with a list of companies to boycott.

(posted on www.independent.co.uk, 16 July 2012)

Such reactionary commentary, now archived on newspaper websites, social media threads and assorted social media including blogs, provide both qualitative and sustained criticism of the inroads of corporate sponsors in sport, and a staunch rebuke to the 'sentiment' that such corporations are the true 'gamesmakers' of major sporting events. The idea that sponsorship is a benevolent force in sport is both problematic and increasingly critiqued by a range of competing stakeholders in sport including its consumers (Horne, 2006).

\section{Global Sports Organisations and Social Media}

The media has been central to the evolution and economic development of professional sport throughout its history (Holt, 1989; Bose, 2012). In the latter half of the Twentieth Century the link between global sports organisations such as the IOC, FIFA and North American mega-brands such as the NBA, has been commercially tied to the economics of the media, in particularly television, which has thereby had a strong influence on the economics of sport (Gratton and Solberg, 2007). Hutchins and Rowe (2012: 47) illustrate a sense of complacency in the 'media sports content economy', which is born of cultural as well as economic dependency and conservatism. 
The rise of social networks, and the kinds of production and distribution practices it has fostered, is now transforming the communications strategies of those sports organisations willing to explore and experiment with developing new forms of media relations which exploit the communication power (Castells, 2009) of digital media. This process has been ongoing for more than a decade (Boyle and Haynes, 2004), but is now rapidly advancing with rapacious intent. A decade ago the barrier to online and mobile sports development proved to be a broadband infrastructure that was not robust enough or extensive in its reach. The rise of fast broadband connections and $3 \mathrm{G}$ and $4 \mathrm{G}$ has helped to erode this barrier. Examples of the fusion of television and the Internet include the Indian Premier League's contract with Google to transmit live coverage of every match in the 2010 season on its social media site YouTube, and Total College Sports run by global sports media company Perform Group whose corporate website claims 20million unique viewers per month to its ePlayer which is embedded in more than 250 national and regional news outlets in the United States.

These developments are not only significant commercial partnerships, but also provide differentiated social media experiences for fans and consumers. Many sports clubs and franchises have developed branded YouTube channels, tapping in to a realisation that fans are willing to download both live and recorded streamed video to keep in touch with their favourite team. The innovation of sports branded applications (apps) for mobile technologies such as $3 \mathrm{G}$ and $4 \mathrm{G}$ smartphones and networked tablet technologies have spurred the development of online sports. For example, Fanatix.com is a sports app that launched in 2011, 
initially as messaging vehicle to connect fans at events and at home during the game or match. By 2012 it had evolved from a messaging app, to one that was also a sports news aggregator and attempting to engage with fans beyond the confines of the event itself, be it a football or tennis match, as the rise of he smart phone gave 24/7 mobile global access to dedicated sports fans. These types of technologies have been welcomed by sport because they offer far more control over the networked media experience than technologically open platforms such as the Web. Apps effectively offer a 'walled garden' approach to networked media sport, and ensure clarity of copyright control and user interface. They also enable micropayments, advertising and online gaming, creating new revenue streams and business opportunities.

Where social media does present a challenge to global sports organisations is the less regulated technologies of blogs and micro-blogs. A number of previous studies have illustrated the challenges faced by sports organisations in the management of 'information accidents' (Hutchins and Rowe, 2012), where scandals and public criticism which may harm the sport, individual athletes and teams, sponsors and associated commercial partners (Boyle and Haynes, 2012). Most crucially, issues can arise from both within and outside the areas of control of a sport, and understanding multiple publics and stakeholders, and how to manage their expectations, attitudes and behaviour is now a full time occupation of communications managers. Indeed this trend is prevalent across the Public Relations industry, with reputation management and online social media profile identified by the sector as the contemporary challenges for PR professionals in 2012. The tensions between freedom and control in networked media sport are 
redolent here. The global sports industries propound the virtues of the widening choice for sports fans, and at the same stroke, nervously look over their shoulders to ensure that the integrity of their sport and their commercial partners are not compromised in any way. Of course these are not uncontested areas. The US Olympic athletes in particular seemed unhappy about not being able to namecheck their sponsors on platforms such as Twitter and Facebook. The even organised a Twitter hashtag \#WeDemandChange and \#Rule40, to attempt to pressure the IOC. How you police this type of regulation is also a challenge for organisations and indeed breeches of the code did take place, and went largely unpunished. However, expect a new modified set of regulations for athletes in Rio 2016, as these emerging battle lines continue to get drawn.

As a matter of course, and now standard governance practice, most global sports organisations have introduced guidelines and regulations on social media activity associated with their events and of the athletes and teams competing in their competitions. Analysis of blogging during the 2008 Beijing Olympics by Hutchins and Mokosza (2010) suggested that while the threat of a major scandal never materialised, the overbearing information management and control of the IOC introduced a new level of surveillance to the media activities of athletes and teams. This policy carried through to London 2012 where some confusion reigned as to what athletes were allowed to do and the kinds of engagement they could have with the public. The IOC guidelines (IOC, 2012) encouraged 'participants and other accredited persons to post comments on social media platforms or websites and tweet during the Olympic Games' but forbid video, taken on a smartphone for instance, being broadcast on any social media 
platform. In the Olympic village, athletes could post photographs, but to do so required full permission of anyone in the frame and images could not be exploited for commercial purposes. The word Olympic could be used as a point of reference, but no association could be made with third parties, and the logo's and emblems of the IOC and LOCOG could not appear in photographs. These and more restraints represent an attempt to micro-manage the use of social media by athletes and ensure compliance with the commercial security of the Games and its commercial partners.

Not all sports competitions have so stringent approach to managing social media. The sport of cricket has followed an 'empowered approach' which understands the opportunities for personal communication in social networks, but also flags up the responsibilities and risks that are associated with it. Unfortunately, the sport has been drawn in to a number of controversies primarily based on the behavior of international players, and their comments and criticisms of the sport, fellow cricketers and management via networked media technologies. In 2012 the star English cricketer Kevin Pietersen found himself at the centre of a storm over Blackberry messages he had sent to opposition players in the South African team that purportedly criticized the then England captain Andrew Strauss in defamatory language. The player was withdrawn from the English Test squad and his international career placed in serious doubt. The player missed the World T20 finals in Sri Lanka, and was obliged to make a public apology over the affair in order to be reinstated to the England squad. Pietersen had also been the target of a parody Twitter account 'KP Genius' set up by a cricket fan and friends to a number of high profile players. Pieterson claimed the spoof account had 
been fed stories by fellow England cricketers Graeme Swann and James Anderson, which poked fun at Pieterson's aloof behavior in the dressing room. The whole series of events undermined attempts by the ECB to pursue a more enlightened approach to social media, ultimately damaging public confidence in their management and structures of governance.

Episodes of this nature provide evidence of major sports organizations struggling to maintain control over networked media, which ultimately have the potential to damage relations with sponsors and media partners. Similar controversies have occurred in football (Boyle, 2012), tennis (Boyle and Haynes, 2013), golf (Boyle and Haynes, 2012) and during the London Olympics when Swiss footballer Michael Morganella was dismissed and sent home from the Games after making a racist comment about a South Korean competitor. In so many of these cases, including the Pieterson story, it is the instantaneous velocity of communications, from the banal and ephemeral moment of thumbing a text or 'tweet' to its wider public reception and re-distribution in to mainstream media, that networked social media has introduced something quite different into the sport-media nexus.

As the culture and volume of social media messages by athletes shows no signs of abating, it is the interface with established media, journalists, broadcasters and online publishers, which presents a challenge to orthodox media relations. Increasingly sports organisations have taken a proactive approach to social media, not only encouraging use of Facebook and Twitter, but also developing communications policies, which foster positive public relations through 
networked media sport. In the lead up to London 2012, the English Football Association's Women's Super League developed a digital ambassador programme to provide an insight into the lives of leading players and encourage more girls and women in to engage in the sport. More proactive communications policies, utilizing the power of social networks, can therefore help some sports, particularly those trying to build their profile with various publics, to directly intervene in the communications process as part of wider strategic objectives.

\section{Sports Journalism, Media Relations and Social Media}

Another way in to understanding the impact of networked media sport is to look at the practices of sports journalism, both in the everyday work of the journalist, and the narratives and forms of content they produce. Digitisation has impacted on journalism at a range of levels. Structurally journalism organisations are struggling to find viable business models to sustain funded professional journalism, in an era in which news content can appears ubiquitous and often free at the point of consumption.

Professionally the impact of this structural change and the manner in which technology has reshaped practice for journalists has been documented elsewhere (Boyle, 2006). Social media has quickly become an increasingly important element of the day-to-day life of journalists, both those working in sports and also other journalistic arenas (Boyle, 2012). Sports journalists use social media as a news feed, to follow players, journalists and supporters. They 
use it to promote their own profile and that of the organisation they are working for, as well as to engage in real time conversations with readers and other sporting stakeholders.

Again these changes need to be viewed as part of longer process that has seen sports journalists - particularly those in the print sector - and their unique access to a 'ringside seat' at sporting events alter and erode over the years (Koppet, 2003). Initially this occurred through the advent of radio, then the arrival of television and subsequent dedicated sports channels and more recently the rise of the internet from the mid 1990s and now social media. As football journalist Kevin McCarra from The Guardian has reflected:

I believe that it is in football that the relationship between writer and reader has most changed, particularly since those roles are no longer fixed. Access to the internet, I am glad to say, has done away entirely with the silly assumption that journalists have access to a higher knowledge. Countless websites cover all aspects of football in virtually every nation. If any player at a World Cup is an unknown quantity it will be purely because the research has not been carried out with sufficient thoroughness [] Websites, whether statistical, solemn, esoteric or comic, disseminate limitless quantities of information about even the most obscure footballers and managers. The press fool themselves if they suppose for an instant that they can be a priesthood who own a sacred knowledge (McCarra, 2010) 
Thus the challenges on sports journalists to deliver something distinctive are increased, as they are in other areas of journalism. However it would be wrong also to view sports journalism as past its sell by date. Despite some of the hyperbole that surrounds the new age of citizen journalism, we are not all journalists yet (Tunney and Monaghan, 2010).

It is often only when mainstream journalists pick up and run with stories that they gain mainstream traction in public profile, even if the origins of these stories may lie among the plethora of bloggers and online commentators that can be found around online sporting discourse. Social media has shortened the timescale in which a 'scoop' can retain its exclusive value to a journalist. The issue of the pace of information flow has resulted in the always-on journalist and, as we've noted above, raised issues for professional communicators working in the sports arena.

Two examples highlight some of these issues and the intertwining of journalism, PR and sports. When Liverpool FC's Luis Suarez refused to shake the hand of Manchester United's Patrice Evra at the league match between the clubs in February 2012 it was the latest instalment in a very public falling out of the players that resulted in the FA finding Suarez guilty of making racist comments made at the Manchester United player. However what happened next signalled how digital media had changed the environment within which sporting events and their participants now operated. For the then Liverpool manager Kenny Dalglish, it was an example of how he had simply failed to adapt to a media culture that had evolved since his previous time at the club twenty years earlier. 
As live television coverage of the non-handshake at the start of the match was broadcast, so social networking sites reported and commented on this event. Yet when Dalglish was interviewed after the match, live on television, he not only indicated that he was unaware that Suarez had refused to shake hands with Evra, but accused the media of inflaming the situation. This performance from Dalglish drew strong criticism from journalists and further damaged the reputation of the club. Both Dalglish and Liverpool later apologised for the behaviour of Suarez that day, but by then the racism story that should have ended that day had been given fresh impetus. Liverpool launched an internal enquiry, presumably asking how Dalglish could be allowed to carry out a live post match interview seemingly unaware that the incident (which he claimed he know nothing about) had been seen around the world, had gone viral on social networks and was being extensively commented on by fans online. A PR professional with a smartphone would have been aware of the damage being done to the club's reputation even 10 minutes after the incident. The fact that Ian Cotton, the club's Director of Communication left Liverpool (having been there for 16 years), just three months later also suggested that Dalglish was not someone who felt he needed a communications expert to tell him how to deal with the media, yet that is preciously what is needed in the digital sports age.

The rise of real time social media have also forced sports bodies to re-think their strategies regarding media relations. The English Premier League (EPL) doubled its communications team in early 2012, by hiring a four strong social media team as they became increasingly concerned that the voice of the EPL was not being 
heard though its digital media platforms (PR Week, 17, Feb., 2012). While within the English FA the internal debate was about the location of the social media element of its communications and whether this should be located within the Marketing arm of the organisation or within the PR/Comms part of the institution. Both organisations have recognised that social media allow them to spread news in real-time to stakeholders, gives them a space to address crisis situations quickly and in so doing helps protect their brand identity while ensuring that people are getting accurate information about the organsiation. In this sense we would argue that viewing social media solely through a marketing lens misses the broader communicative role that these media platforms are now helping to facilitate.

\section{Conclusion}

As we write late in 2012, the media profile of sport in the UK has never been higher. The summer saw the success of Team GB at the London 2012 Olympics displace other news coverage across media outlets across the UK, while the BBC, using its digital capacity carried every event online. The subsequent Paralympics, allowed Channel 4 to record some of its largest audience figures for a decade, while British wins for Bradley Wiggins in the Tour de France, Andy Murray at the US Tennis Open and the success of the European Ryder Cup golf team in October all resulted in extensive media and public profile been given to sport and sporting achievement. 
At the core of these collective experiences has been television (both FTA and Pay-TV) complemented by social and online media and a print media that has often been able to focus on the backstory that the live mediated event has framed. All this suggests that sports intrinsic appeal remains undiminished despite the corporate edifice that now accompanies elite sports events and its culture. This makes sports an extremely appealing cultural vehicle for the continued exploitation by a range of commercial and other stakeholders with a host of agendas from revenue generation to social inclusion projects. To this end the role of PR and its linkage with sports media coverage will continue to evolve and develop.

The synergies between the sports and entertainment industries discussed elsewhere (Boyle, 2006) are clear in 2012. When F1 driver Lewis Hamilton announced he would be leaving McLaren for Mercedes at the end of the season, Simon Fuller of XIX Entertainment, whose stable of talent spans the music, entertainment and sports arenas, carried out the deal. Andy Murray's first Grand Slam tennis victory just a few weeks earlier meant that Fuller had enjoyed an extremely lucrative couple of months with Murray also part of the XIX Entertainment team. For some commentators the deal breaker for McLaren was their refusal to allow their drivers to retain their image rights. Mercedes were happy to sign away Hamilton's image rights, thought to be worth in the region of $£ 10$ million a year. This arrangement is also indicative of how issues around rights, copyright and policing the digital environment are all part of an emerging research agenda for those examining the media sports relationship in the digital age. 
This will present a new set of challenges to sports stakeholders and its custodians. In an age of screens and mobile media, do you attempt to police media usage in stadiums to protect rights holders (the IOC position), or be more relaxed about this as in the case of the San Francisco 49's owner Jed York who said:

that his new stadium has to be equipped for the modern fan who doesn't just want to watch the game but also to share, comment, monitor their fantasy team, make bets or even just keep their kid calm with a video (Shortt, 2012: Executive Summary).

For York then, rather than lock down a stadium, he wants to drive a younger audience to the event, who he feels will not come without a digitally robust environment for the next generation of media users. The social media genie is out of the bottle, but rather than displace television, it will work with this platform as sports remain at the forefront of this emerging media milieu for the foreseeable future.

\section{Bibliography}

Boyd, D and Ellison, N (2007) Social Network Sites: Definition, History, and Scholarship. Journal of Computer-Mediated Communication 13(1): 210-30. 
Bose, M. (2012) The Spirit of the Game: How sport made the modern world, London: Constable.

Boyle, R. (2012) Social media sport? Journalism, public relations and sport, in R. Krøvel and T. Roksvold (Eds) We Love To Hate Each Other: Mediated Football Fan Culture. Gothenburg: Nordicom.

Boyle, R. and Haynes, R. (2004) Football in the New Media Age. London: Routledge.

Boyle, R. (2006) Sports Journalism: Context and Issues, London: Sage.

Boyle, R. and Haynes, R. (2012) Sport, the media and strategic communications management, in L. Trenberth and D. Hassan (Eds) Managing Sport Business: An Introduction. London: Routledge. 318-337.

Boyle, R. and Haynes, R. (2013) Sports journalism and social media: A new conversation? in B. Hutchins and D. Rowe (Eds) Digital Media Sport. New York: Routledge.

Castells, M. (2009) Communication Power. Oxford: Oxford University Press.

Gratton, C., Liu, D., Ramchandani, G and Wilson, D. (2012) The Global Economics of Sport. London: Routledge. 
Gratton, C. and Solberg, H. A. (2007) The Economics of Sports Broadcasting. London: Routledge.

Holt, R. (1989) Sport and the British: A modern history, Cambridge: Clarendon Press.

Horne, J. (2006) Sport in Consumer Culture. London: Palgrave.

Hutchins, B. and Mikosza, J. (2010) 'The Web 2.0 Olympics: Athlete Blogging, Social Networking and Policy Contradictions at the 2008 Beijing Games,' Convergence: The International Journal of Research into New Media Technologies, 16(3): 279-297.

Hutchins, B. and Rowe, D. (2012) Sport Beyond Television: The Internet, Digital Media and the Rise of Networked Media Sport. New York: Routledge.

IOC (2012) IOC Social Media, Blogging and Internet Guidelines for participants and other accredited persons at the London 2012 Olympic Games, accessed at http://www.olympic.org/Documents/Games London 2012/IOC Social Media B logging and Internet Guidelines-London.pdf, 19 September 2012.

Koppett, L. (2003) The Rise and Fall of the Press Box, Toronto: Sport Classic Books. 
Lewis, R and Kitchin, P (2011) New Communications Media for Sport, in M. Hopwood, P. Kitchin and J. Skinner (Eds) Sport Public Relations and Communication. London: Routledge. 187-214.

McCarra, K. (2010) Open Door, The Guardian, 28 June.

Shortt, A. (2012) Social Media in Sport, London: Sportsbusiness.

Tunney, S. and Monaghan, G. (eds.) (2010) Web Journalism: A New Form of Citizenship? London: Sussex Academic Press.

Vamplew, W. (2004) Pay Up and Play the Game: Professional Sport in Britain, 1875-1914. Cambridge: Cambridge University Press. 